\title{
Biological, Pathological, and Molecular Characteristics of a New Potyvirus, Dendrobium Chlorotic Mosaic Virus, Infecting Dendrobium Orchid
}

\author{
Chih-Hung Huang, ${ }^{1,2}$ Chia-Hsing Tai, ${ }^{2}$ Ruey-Song Lin, ${ }^{3}$ Chung-Jan Chang, ${ }^{4}$ and Fuh-Jyh Jan ${ }^{1,2,5, \dagger}$ \\ ${ }^{1}$ Program in Microbial Genomics, National Chung Hsing University and Academia Sinica, Taichung 40227, Taiwan; ${ }^{2}$ Depart- \\ ment of Plant Pathology, National Chung-Hsing University, Taichung 40227, Taiwan; ${ }^{3}$ Department of Horticulture, National \\ Chung-Hsing University, Taichung 40227, Taiwan; ${ }^{4}$ Department of Plant Pathology, University of Georgia, Griffin, GA \\ 30223, U.S.A.; and ${ }^{5}$ Advanced Plant Biotechnology Center, National Chung-Hsing University, Taichung 40227, Taiwan
}

\begin{abstract}
Dendrobium smillieae is one of the popular orchids in Taiwan. This report describes a new potyvirus tentatively named Dendrobium chlorotic mosaic virus (DeCMV) causing chlorotic and mosaic symptoms in $D$. smillieae. Enzyme-linked immunosorbent assay (ELISA) tests using six antisera against orchid-infecting viruses revealed that only a monoclonal antibody against the potyvirus group reacted positively with crude saps prepared from a symptomatic dendrobium orchid. Potyvirus-like, flexuous, filamentous particles were observed under an electron microscope, measuring approximately 700 to $800 \mathrm{~nm}$ in length and 11 to $12 \mathrm{~nm}$ in diameter. Sequence analyses revealed that DeCMV coat protein gene shared 59.6 to $66.0 \%$ nucleotide sequence identity and 57.6 to $66.0 \%$ amino acid sequence identity, whereas the DeCMV complete genome shared 54.1 to $57.3 \%$ nucleotide sequence identity and 43.7 to $49.5 \%$ amino acid sequence identity with those other known

potyviruses. These similarity levels were much lower than the criteria set for species demarcation in potyviruses. Thus, DeCMV can be considered a new potyvirus. The whole DeCMV genome contains 10,041 nucleotides (GenBank accession no. MK241979) and encodes a polyprotein that is predicted to produce 10 proteins by proteolytic cleavage. In a pathogenicity test, results of inoculation assays demonstrated that DeCMV can be transmitted to dendrobium orchids by grafting and mechanical inoculation, as verified by ELISA and western blot analyses using the DeCMV polyclonal antiserum and by reverse transcription polymerase chain reaction using the coat protein gene-specific primers The inoculated orchids developed similar chlorotic and mosaic symptoms. In conclusion, DeCMV is a novel orchid-infecting potyvirus, and this is the first report of a new potyvirus that infects dendrobium orchids in Taiwan.
\end{abstract}

Dendrobium orchids, composed of more than 1,000 species (Takamiya et al. 2011), are important ornamental plants commonly used for cut flowers or potted plants. Dendrobium orchids are widely cultivated in many countries of Asia, New Guinea, and Australia (Fernando and Ormerod 2008; Yan et al. 2015). Some species of Dendrobium orchids containing compounds with demonstrated antioxidant and antitumor activities (Takamiya et al. 2011) have long been used as traditional Chinese medicinal plants.

As with all plants, cultivation of orchids is often hindered by viral diseases. At least 57 viral species have been reported to infect orchids (Lawson and Hsu 1995; Lee et al. 2016; Zettler et al. 1990; Zheng et al. 2010). Many viruses that belong to the genera Potexvirus, Potyvirus, Tospovirus, Cucumovirus, Closterovirus, Carlavirus, Carmovirus, Sobemovirus, or Tobamovirus can infect orchids. Among them, Cymbidium mosaic virus (CymMV) (Zettler et al. 1990), Odontoglossum ringspot virus (ORSV) (Jensen and Gold 1951; Hu et al. 1993), Cucumber mosaic virus (CMV) (Inouye 1969), Dendrobium mosaic virus (DeMV) (Inouye 1976; Hu et al. 1995), Dendrobium vein necrosis virus (DVNV) (Lesemann 1977), Ceratobium mosaic virus (CerMV) (Mackenzie et al. 1998), Orchid fleck virus (OFV) (Kondo et al. 2003), and Impatiens necrotic spot virus (INSV) (Zhang et al. 2010) have been reported to infect Dendrobium. In

${ }^{\dagger}$ Corresponding author: F.-J. Jan; fjjan@nchu.edu.tw

Funding: This work was partially supported by grants from the Ministry of Science and Technology (MOST), Taiwan (105-2313-B-005-019-MY3) and by the Advanced Plant Biotechnology Center from The Featured Areas Research Center Program within the framework of the Higher Education Sprout Project by the Ministry of Education (MOE) in Taiwan.

The author(s) declare no conflict of interest.

Accepted for publication 24 January 2019.

(c) 2019 The American Phytopathological Society
Taiwan, only seven viruses have been reported to infect orchids. These include CymMV (Hsieh Shih and Han 1975; Wey 1988), ORSV (Ko 1988; Zheng et al. 2010), CMV (Ko 1988), OFV, Carnation mottle virus (CarMV) (Zheng et al. 2011), Phalaenopsis chlorotic spot virus (PhCSV) (Zheng et al. 2011), and Capsicum chlorosis virus (CaCV-Ph) (Zheng et al. 2008b). Among them, only CymMV (Hsieh Shih and Han 1975), ORSV, and CMV (Inouye and Leu 1983) have been reported to infect Dendrobium orchids in Taiwan.

The genus Potyvirus is the largest group of the plant positivestrand RNA viruses (Revers and García 2015; Shukla et al. 1994). In total, there are 168 potyvirus species currently being recognized by the International Committee on Taxonomy of Viruses (ICTV 2018 release; https://talk.ictvonline.org/taxonomy/). The species demarcation criteria for potyviruses suggested by ICTV are based on the complete sequence of the large opening reading frames (ORFs) set at $<76 \%$ nucleotide sequence identity and $<82 \%$ amino acid sequence identity (Adams et al. 2005b; Wylie et al. 2017). Potyviruses have relatively narrow host ranges compared with many other plant viruses (Wylie et al. 2017) and are primarily transmitted by aphids in a nonpersistent manner ( $\mathrm{Ng}$ and Perry 2004). Virions of potyviruses are flexuous filamentous particles with no envelope, often measuring 11 to $13 \mathrm{~nm}$ in diameter and 680 to $900 \mathrm{~nm}$ in length. A potyvirus genome consists of a positive-sense and single-stranded RNA of about $9.7 \mathrm{~kb}$ in size, in which a viral genome-linked protein (VPg) is covalently bound to the $5^{\prime}$ end and a polyadenylated tail is attached to the 3' end (Adams et al. 2012; Wylie et al. 2017). A potyvirus genome contains a single ORF encoding a polypeptide that is predicted to be processed for 11 functional proteins. The small ORF termed "pretty interesting potyvirus ORF" (PIPO) encodes a P3N-PIPO protein via the RNA polymerase slippage mechanism. PIPO has been shown to be essential for intercellular movement of the viruses in Potyviridae (Chung et al. 2008; Olspert et al. 2015; Revers and García 2015; Rodamilans et al. 2015; Wylie et al. 2017). The large ORF encodes a polyprotein that is subsequently self-cleaved into 10 polypeptides via proteolysis at specific cleavage sites (Adams 
et al. 2005a; Urcuqui-Inchima et al. 2001; Wylie et al. 2017). These include a P1 protein, a helper-component proteinase (HC-Pro), a P3 protein, a 6-kDa peptide (6K1), a cylindrical inclusion protein, a second 6-kDa peptide (6K2), a VPg, a nuclear inclusion "a" (NIa) protease, a nuclear inclusion "b" protein $(\mathrm{NIb})$, and a coat protein $(\mathrm{CP})$ (Adams et al. 2012; Karasev and Gray 2013; Revers and García 2015; Riechmann et al. 1992; Wylie et al. 2017). Most of the potyvirus proteins have multiple functions and often cooperate with each other during the viral infection cycle.

In 2009, dendrobium orchid leaves showing mosaic and chlorotic symptoms were observed in an orchid farm in Taiwan. Here, we present the biological, pathological, and molecular characteristics of the virus and demonstrate that the putative causal agent is a novel potyvirus infecting Dendrobium orchids. The newly identified virus was tentatively named Dendrobium chlorotic mosaic virus (DeCMV).

\section{Materials and Methods}

Diseased orchid and indicator plants. A dendrobium (Dendrobium smillieae F. Muell.) plant (plant ID 98-De-31) showing chlorotic and mosaic symptoms was collected from an orchid farm located in Puli Township (Nantou County, Taiwan) in 2009. Another dendrobium plant (plant ID 106-De-1) showing similar symptoms was collected from Tainan City, Taiwan, in 2017. Symptomatic dendrobium leaves (plant ID 98-De-31) were ground in $0.01 \mathrm{M}$ phosphate buffer $(\mathrm{pH} 7.0)$, serially diluted 20 -fold, and inoculated to healthy orchids and other indicator plants, consecutively, by rub inoculation. Plants used for inoculation included Chenopodium quinoa, C. amaranticolor, Datura stramonium, Nicotiana benthamiana, N. glutinosa, N. occidentalis, $N$. rustica, $N$. edwardsonii, N. tabacum var. Xanthi, N. tabacum var. Samsun, N. tabacum var. Hicks, $N$. tabacum cv. White Burley, Solanum lycopersicum, Capsicum annuum, Vigna unguiculata, and Citrullus lanatus. In addition, 5-cm stem cuttings of the dendrobium plant (98-De-31) were grafted to healthy ones (D. smillieae) using the wedge grafting method as described by Dijkstra and de Jager (1998). Inoculated plants were maintained in an insect-proof greenhouse located in the National Chung Hsing University (NCHU, Taichung, Taiwan) for at least 1 month for symptom development.

Indirect enzyme-linked immunosorbent assay (indirect ELISA). Indirect ELISA was performed using the previously described procedure (Chang et al. 2010; Chen et al. 2005). Crude sap prepared from the 98-De31 orchid was initially examined by ELISA using polyclonal antisera against CymMV, ORSV, CMV, CaCV, and CarMV. A commercially available ELISA kit (Agdia, Elkhart, IN) containing the monoclonal antibody for detecting potyviruses was also used in the ELISA assay. A polyclonal antiserum against the newly identified DeCMV was also prepared (see below for details) and used for indirect ELISA analysis. The test plants after being inoculated by grafting or by rub inoculation were analyzed by ELISA using antiserum against DeCMV. All antisera were prepared in New Zealand white rabbits after injection with recombinant viral CPs as described previously (Jan and Yeh 1995).

Electron microscopy. Crude saps prepared from symptomatic leaves of plant 98-De-31were loaded on formvar-coated carbon grids. The samples were stained with $2 \%$ uranyl acetate $(\mathrm{pH} 4.2)$ and analyzed with a JEOL JEM-1400 transmission electron microscope (JEOL, Tokyo, Japan) as described previously (Chen et al. 2005).

Expression of DeCMV CP in Escherichia coli and production of a polyclonal antiserum. A specific primer pair, FJJ 2010-41 and FJJ 2010-42 (Table 1), was used to amplify partial CP-coding region of DeCMV. The resultant fragment was cloned into the protein expression vector pET 21a (Novagen, Darmstadt, Germany) to generate a pET-21a-98-De-31 CP-His construct. The plasmid was propagated in E. coli BL 21 (DE3) (Novagen). The DeCMV CP was expressed and purified according to the protocol as described in the manual for the pET system (Novagen) and used for the production of a polyclonal antibody.

Western blotting. Western blotting was performed following the procedures as described previously (Zheng et al. 2008a). Crude proteins were prepared from healthy and virus-infected dendrobium leaves, separated by $10 \%$ SDS polyacrylamide gel electrophoresis, and electro-blotted to a polyvinylidene difluoride membrane (Immobilon-P, Merck Millipore, Darmstadt, Germany). The membrane was incubated with the polyclonal antiserum against DeCMV $\mathrm{CP}$ at a 5,000-fold dilution in the TSW buffer $(10 \mathrm{mM}$ Tris base, $0.9 \%$ sodium chloride, $0.25 \%$ gelatin, $0.1 \%$ Triton $\mathrm{X}-100,0.02 \%$ SDS, $\mathrm{pH}$ 7.4), followed by incubation with a peroxidaseconjugated goat antirabbit secondary antibody (1:10,000; Jackson Immunoresearch, Baltimore, MD). The chemiluminescent signal was developed using Western Lightning ECL Pro (PerkinElmer, Waltham, MA). Images were captured and stored using a ChemiDoc MP imaging system (Bio-Rad, Hercules, CA).

Molecular cloning and sequence analyses. Total RNA was prepared from healthy and symptomatic dendrobium leaves by the method described by Napoli et al. (1990). The reverse transcription polymerase chain reaction (RT-PCR) was carried out according to the method described by Jan et al. (2000). The degenerate primer

Table 1. Primers used for cloning Dendrobium chlorotic mosaic virus

\begin{tabular}{|c|c|c|}
\hline Primer & Sequence $\left(5^{\prime}-3^{\prime}\right)$ & Location \\
\hline Oligo d(T) & GAGAGAGACTCGAGTTTTTTTTTTTTTTTTTT & Poly (A) tail \\
\hline FJJ 2005-71 & GTBGATYTKACACMACAYRWHCC & $\operatorname{VPg}(\mathrm{F})$ \\
\hline FJJ 2005-73 & CAGTTGATGGCTGACCACTATTGT & $\mathrm{NIb}(\mathrm{R})$ \\
\hline FJJ2011-73 & CTTACACCACGATGGAAAGC & NIa (R) \\
\hline FJJ 2011-78 & GATGARTGYCAYGTKC & $\mathrm{CI}(\mathrm{F})$ \\
\hline FJJ 2011-82 & GCTTCTGACGTTGAGACCTG & $\mathrm{CI}(\mathrm{R})$ \\
\hline FJJ 2011-139 & TAYMGHGTTGGWGG & HC-Pro \& P3 (F) \\
\hline FJJ 2011-171 & CACTGCGATGTAGTGCAATC & HC-Pro $(\mathrm{F})$ or P3 (R) \\
\hline FJJ 2011-221 & СТСТTCСТCAGATGCATAAC & P1 (F) or HC-Pro (R) \\
\hline FJJ 2012-45 & AAAYTRWAAMAAMTCA & $5^{\prime} \mathrm{UTR}(\mathrm{F})$ \\
\hline FJJ 2013-1 & GAATCCTTAAACGAGGTGTC & $\mathrm{P} 1(\mathrm{R})$ \\
\hline FJJ 2013-24 & CAGTTGTCTCGTATTCAGTGTAC & P1 (R) \\
\hline FJJ 2013-49 & ССТСТСTAAGAATGTTCCGAG & P1 (R) \\
\hline FJJ 2010-41 & GGATCCATGTCTGGCTCTCTTG & $\mathrm{CP}(\mathrm{F})$ \\
\hline FJJ 2010-42 & CTCGAGAGAGTGCCTCATGCCGA & $\mathrm{CP}(\mathrm{R})$ \\
\hline FJJ 2017-69 & CATCAAATGAGTGGAGAACA & $\mathrm{CP}(\mathrm{F})$ \\
\hline FJJ 2017-70 & TCTATATACGCTTCAGCAGCGT & $\mathrm{CP}(\mathrm{R})$ \\
\hline Pot1 & GACTGGATCCATTBTCDATRCACCA & $\mathrm{CP}(\mathrm{R})$ \\
\hline Pot2 & GACGAATTCTGYGAYGCBGATGGYTC & $\mathrm{NIb}(\mathrm{F})$ \\
\hline Hrp5 & ATGATHGARKCNTGGGG & $\mathrm{NIb}(\mathrm{F})$ \\
\hline
\end{tabular}


pairs specifically targeting potyviruses (Hrp5/Pot1) (Chen et al. 2006; Colinet and Kummert 1993), tospoviruses (gL4435c/ gL3637) (Chu et al. 2001), tobamoviruses (Tob-Uni1/Tob-Uni2) (Letschert et al. 2002), and potexviruses (Potex1/Potex2) (Gibbs et al. 1998) were used to detect viruses of the respective viral genus. The other degenerate primer pair, Hrp5/Oligo d(T) $)_{18}$ was used in RTPCR to obtain the full-length cDNA fragment corresponding to the DeCMV CP.

The first strand cDNA was synthesized by a SuperScript III reverse transcription (Invitrogen, Carlsbad, CA) according to the manufacturer's protocol and used in PCR. All oligonucleotide primers used in this study are listed in Table 1. To determine the sequence of the $5^{\prime}$ untranslated region (UTR) of the DeCMV genome, the first strand of cDNA was synthesized by SuperScript III with reverse virus-specific primer FJJ 2013-24. The repetitive d(C) tails were added with terminal deoxynucleotidyl transferase (TdT) (Takara Bio, Shiga, Japan). Double-stranded cDNA was generated by PCR using the primer oligo $d(G)_{16}$ paired with FJJ 2013-49. The fulllength DeCMV sequence was assembled from nine overlapping fragments independently amplified and sequenced with various primers (Table 1). PCR amplification was performed using TaKaRa LA Taq DNA polymerase (Takara BIO, Shiga, Japan) in a thermal cycler (PTC-200, MJ Research, Waltham, MA). The conditions used for amplification were as follows: an initial denaturation step at $94^{\circ} \mathrm{C}$ for $5 \mathrm{~min}$, followed by 35 cycles of denaturation at $94^{\circ} \mathrm{C}$ for $1 \mathrm{~min}$, annealing at $50^{\circ} \mathrm{C}$ for $1 \mathrm{~min}$, and extension at $72^{\circ} \mathrm{C}$ for $2 \mathrm{~min}$, and one final extension at $72^{\circ} \mathrm{C}$ for $10 \mathrm{~min}$. PCR products were cloned into a TOPO-pCRII TA vector (Invitrogen) according to the manufacturer's instructions.

Sequencing was performed using the automatic DNA sequencer ABI PRISM 3730 (Applied Biosystems, Hammonton, NJ) available at the Biotechnology Center (NCHU, Taichung, Taiwan). Pairwise comparisons of both nucleotide and amino acid sequences among DeCMV and other members of the Potyvirus genus were performed by the MegAlign program available in Lasergene 7 software (DNASTAR, Madison, WI). Potyvirus full sequences (Table 2) used for viral gene comparison and phylogenetic analysis were retrieved from NCBI GenBank. Phylogenetic analyses were performed with the Clustal W algorithm and the neighbor-joining method with MEGA software version 7.0 (Kumar et al. 2016) and evaluated with 1,000 bootstrap replicates. Two primers, FJJ 2017-69 and FJJ 2017-70 (Table 1), specifically complementary to DeCMV CP-coding sequence, were designed and synthesized to detect DeCMV from field-collected dendrobium plant samples (plant ID 106-De-1).

\section{Results}

Symptomatology of Dendrobium orchid mosaic disease and isolation of the causative virus. A dendrobium orchid (plant ID 98-De-31) showing systemic mosaic chlorosis on leaves (Fig. 1A) was observed in Taiwan. Crude saps were prepared from this symptomatic dendrobium plant and examined by ELISA using antisera against six orchid-infecting viruses: ORSV, CymMV, CMV, CaCV, CarMV, and potyvirus. The 98-De-31 samples reacted positively only with the potyvirus monoclonal antibody (data not shown). The putative causative agent was tentatively named as Dendrobium chlorotic mosaic virus (DeCMV). Crude saps mechanically inoculated into 16 plants species, including two Chenopodium spp., nine Nicotiana spp., D. stramonium, S. lycopersicum, C. annuum, V. unguiculata, and $C$. lanatus resulted in no visible symptoms 30 days postinoculation (dpi) (data not shown). ELISA analysis using the DeCMV antiserum also resulted in negative reactions, confirming that the tested 16 plants $(n=4)$ were not host plants of DeCMV. However, D. smillieae plants inoculated with crude saps prepared from $98-D e-31$ by either mechanical rubbing $(n=4)$ or grafting $(n=5)$ with 98-De-31 all developed chlorotic and mosaic symptoms 75 dpi (Fig. 1B and C). At 75 dpi, ELISA analysis of diseased $D$. smillieae plants using the DeCMV antiserum also resulted in positive reactions. No symptoms were observed in D. smillieae leaves treated with buffer as controls (Fig. 1D). The results were also negative when the DeCMV antiserum was reacted with crude samples prepared from buffer-treated plants.
DeCMV has potyvirus-like particles. Transmission electron microscopy analysis of sap samples prepared from the symptomatic dendrobium orchid (98-De-31) leaves revealed flexuous filamentous particles with negative staining (Fig. 2). The flexuous filamentous particles measured 11 to $12 \times 700$ to $800 \mathrm{~nm}$ in size, resembling those of potyviruses. Similar shapes and sizes of viral particles were also observed in dendrobium leaves inoculated with crude saps prepared from 98-De-31.

Western blotting analysis of crude saps prepared from 98-De-31 and 106-De-1 plants, as well as dendrobium orchids inoculated by a mechanical means and grafting, all resulted in a band of around 30 to $31 \mathrm{kDa}$, as judged in comparison with molecular weight ladders using the antiserum against DeCMV (Fig. 3). DeCMV identified from the 106-De-1 plant apparently had a smaller CP than that found in the 98-De-31 plant, likely owing to the differences of sequence identities between two DeCMV isolates (see below for details).

Characterization of the DeCMV genome. RT-PCR analyses using degenerate primers targeting tobamoviruses, tospoviruses, and potexviruses failed to amplify products from the 98-De-31orchid. The primers amplified expected DNA fragments from respective

Table 2. Comparison of nucleotide (nt) and deduced amino acid (aa) sequences of the coat protein $(\mathrm{CP})$ gene of Dendrobium chlorotic mosaic virus (MK241979) with those of other potyviruses available in NCBI

\begin{tabular}{|c|c|c|c|c|c|}
\hline \multirow[b]{2}{*}{ Virus $^{a}$} & \multirow[b]{2}{*}{ Accession no. } & \multicolumn{2}{|c|}{$\begin{array}{l}\text { Open reading } \\
\text { frames }\end{array}$} & \multicolumn{2}{|c|}{$\mathbf{C P}$} \\
\hline & & nt $(\%)$ & aa $(\%)$ & nt $(\%)$ & aa $(\%)$ \\
\hline BtMV & KY012334 & 56.8 & 49.5 & 60.4 & 57.6 \\
\hline KjMV & NC_016159 & 55.6 & 49.5 & 61.2 & 64.6 \\
\hline BCMV & КМ076650 & 56.0 & 49.1 & 61.0 & 62.1 \\
\hline BaRMV & NC 009741 & 57.3 & 48.9 & 62.1 & 62.4 \\
\hline YBMV & NC_016441 & 56.4 & 48.8 & 61.8 & 62.4 \\
\hline HaMV & NC_015394 & 56.8 & 48.2 & 61.1 & 61.1 \\
\hline SMV & NC_002634 & 56.7 & 48.2 & 60.5 & 61.7 \\
\hline WMV & JF273466 & 56.5 & 48.2 & 61.3 & 61.4 \\
\hline EAPV & AB604610 & 57.3 & 47.8 & 62.4 & 63.6 \\
\hline PPV & NC_001445 & 56.4 & 47.7 & 64.7 & 64.0 \\
\hline CLLV & NC_021196 & 56.7 & 47.0 & 61.5 & 62.1 \\
\hline ZYMV & NC_003224 & 56.1 & 47.0 & 59.7 & 62.0 \\
\hline YMV & NC_004752 & 56.7 & 46.9 & 64.5 & 61.4 \\
\hline NLSYV & JX156421 & 56.4 & 46.9 & 61.2 & 61.6 \\
\hline OrMV & NC_019409 & 56.2 & 46.6 & 62.1 & 66.0 \\
\hline PLDMV & NC_005028 & 56.2 & 46.0 & 62.5 & 61.4 \\
\hline PepYMV & NC_014327 & 55.2 & 45.7 & 63.0 & 61.8 \\
\hline ChiVMV & NC_005778 & 55.5 & 45.3 & 63.7 & 61.3 \\
\hline PepMoV & AF501591 & 55.3 & 45.2 & 64.3 & 61.1 \\
\hline VerVY & NC_010735 & 55.7 & 44.9 & 63.3 & 61.4 \\
\hline PepSMV & NC_008393 & 56.0 & 44.7 & 63.6 & 64.6 \\
\hline BsMoV & NC_014536 & 55.6 & 44.7 & 64.7 & 61.5 \\
\hline BiMoV & NC_014325 & 55.5 & 44.6 & 63.3 & 63.2 \\
\hline SCMoV & NC_014038 & 54.1 & 43.7 & 61.3 & 63.3 \\
\hline TulMV & X63630 & - & - & 65.7 & 63.3 \\
\hline CerMV & AF022443 & - & - & 64.2 & 63.2 \\
\hline SarVY & AF185957 & - & - & 66.0 & 62.9 \\
\hline AmLMV & AJ580021 & - & - & 64.9 & 61.3 \\
\hline DeMV & U23564 & - & - & 59.6 & 60.9 \\
\hline
\end{tabular}

${ }^{a}$ Full names of potyviruses are Amaranthus leaf mottle virus (AmLMV), Araujia mosaic virus (ArjMV), Bean common mosaic virus (BCMV), Basella rugose mosaic virus (BaRMV), Beet mosaic virus (BtMV), Bidens mottle virus (BiMoV), Brugmansia suaveolens mottle virus (BsMoV), Calla lily latent virus (CLLV), Ceratobium mosaic virus (CerMV), Chilli veinal mottle virus (ChiVMV), Dendrobium mosaic virus (DeMV), East Asian Passiflora virus (EAPV), Hardenbergia mosaic virus (HaMV), Keunjorong mosaic virus (KjMV), Narcissus late season yellows virus (NLSYV), Ornithogalum mosaic virus (OrMV), Pepper mottle virus (PepMoV), Pepper severe mosaic virus (PepSMV), Pepper yellow mosaic virus (PepYMV), Plum pox virus (PPV), Papaya leaf-distortion mosaic potyvirus (PLDMV), Sarcochilus virus $Y$ (SarVY), Soybean mosaic virus (SMV), Sunflower chlorotic mottle virus (SCMoV), Tulip mosaic virus (TulMV), Verbena virus $Y$ (VerVY), Watermelon mosaic virus (WMV), Yam mosaic virus (YMV), Yambean mosaic virus (YBMV), and Zucchini yellow mosaic virus (ZYMV). 
plants infected with ORSV, CaCV-Ph, PhCSV, and CymMV (positive controls). RT-PCR using degenerate primers (Hrp5 and Pot1) for potyviruses amplified an expected 600-bp fragment from total RNA prepared from the 98-De-31 orchid (Fig. 4A).

Full-length CP-coding sequence of DeCMV was obtained by RTPCR with a degenerate primer Hrp5 pairing with Oligo d(T) $)_{18}$. An expected 1.4-kb cDNA fragment containing the $\mathrm{CP}$ sequence and the $3^{\prime}$ terminal region and poly A tail was amplified (Fig. 4B). Sequence analysis revealed that the amplified fragment encodes a protein of 347 amino acids, containing the C-terminal of NIb, full-length
$\mathrm{CP}$, and the $3^{\prime}$ UTR. A putative protease cleavage site (VVVHQ/M) between NIb and CP was found in the predicted polypeptide. The DeCMV CP has 272 amino acids with a calculated molecular mass of $31 \mathrm{kDa}$. The DAG motif associated with aphid transmission was found at the $\mathrm{N}$ terminus of $\mathrm{CP}$ (amino acids 7 to 9). Two conserved motifs, MVWCIENG and QMKAAA, commonly found in the CP of potyviruses (Rybicki and Shukla 1992), were also present in the DeCMV CP. The DeCMV CP shared 59.6 to $66.0 \%$ nucleotide identity and 57.6 to $66.0 \%$ amino acid sequence identity with those of 30 potyviruses deposited in GenBank (Table 2).
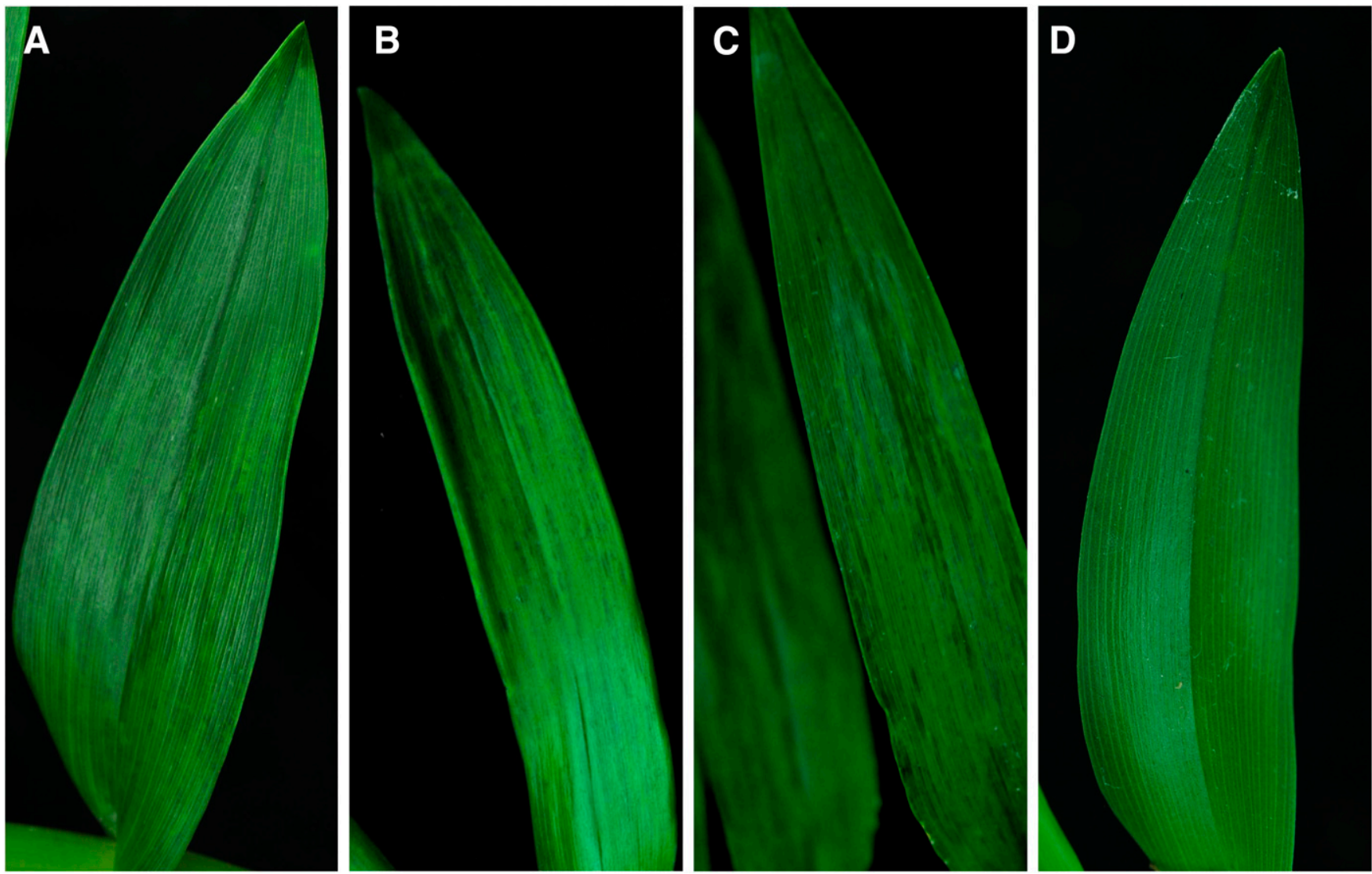

Fig. 1. Symptoms on leaves of dendrobium orchid caused by infection with Dendrobium chlorotic mosaic virus. A, Dendrobium smillieae (plant ID 98-De-31) leaves showing chlorotic and mosaic symptoms. B, Similar symptoms were observed on D. smillieae leaves mechanically inoculated with the sap obtained from 98-De-31. C, Leaves showing similar chlorotic and mosaic symptoms after being graft inoculated with 98-De-31 stems. D, Leaves mechanically inoculated with $0.01 \mathrm{M}$ phosphate buffer were used as negative control.

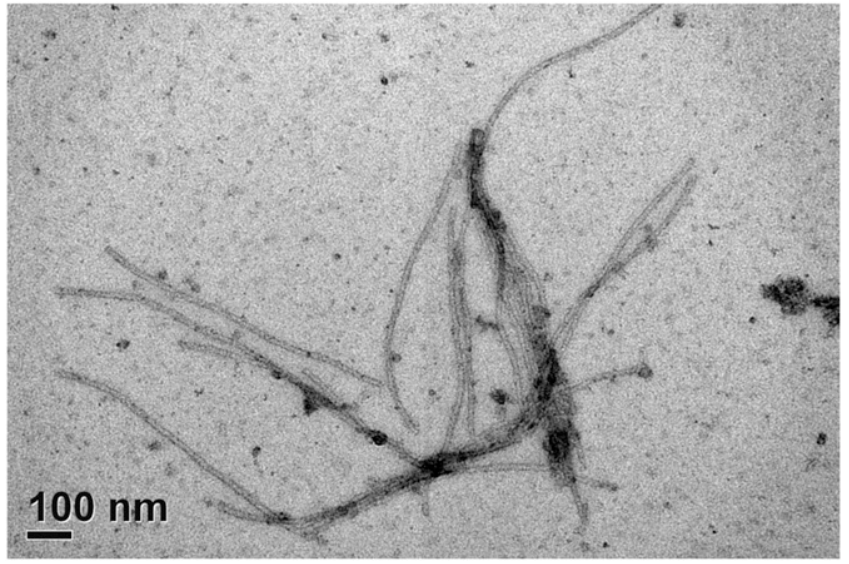

Fig. 2. Electron micrograph of flexuous filamentous viral particles of Dendrobium chlorotic mosaic virus isolated from the leaf tissues of Dendrobium smillieae orchid (98-De-31) via negative staining. Bar represents $100 \mathrm{~nm}$
$\mathrm{kDa}$
98- 106-
G M
$\mathrm{H}$

\section{De-31 De-1}

Fig. 3. Western blotting analysis of Dendrobium chlorotic mosaic virus (DeCMV). The crude saps were extracted from symptomatic Dendrobium smillieae (98-De-31 and 106-De-1) and from orchids after either being grafted (G) or via mechanical inoculation (M) with 98-De-31 stems or crude saps, respectively. Crude protein extracts were separated in a $10 \%$ SDS polyacrylamide gel electrophoresis and reacted with the DeCMV antiserum. Crude saps prepared from plants inoculated with $0.01 \mathrm{M}$ phosphate buffer were used as the mock controls $(\mathrm{H})$. 
Sequences of potyviruses were aligned, and degenerate primers were designed based on the conserved sequences and used in RTPCR to amplify DeCMV sequences. The full-length DeCMV sequence was assembled from sequences of nine overlapping cDNA fragments (Table 1, Fig. 4B). These cDNA fragments were independently amplified and sequenced with various primers. The full-length DeCMV genome was found to contain 10,041 nucleotides (nt) (GenBank accession no. MK241979), including 132 nt at the $5^{\prime}$ UTR and $339 \mathrm{nt}$ at the $3^{\prime}$ UTR. DeCMV genome was found to contain an ORF beginning with an AUG start codon and ending with a UGA stop codon, which encodes a polyprotein of 3,189 amino acids. The DeCMV polyprotein was predicted to be subsequently self-cleaved into 10 proteins, including P1 (48.4 kDa, 1,260 nt), HC-pro $(51.5 \mathrm{kDa}$, 1,365 nt), P3 (40.3 kDa, 1,047 nt), 6K1 (5.8 kDa, $156 \mathrm{nt}), \mathrm{CI}$ (71.4 kDa, 1,902 nt), 6K2 (6.1 kDa, $159 \mathrm{nt}), \mathrm{VPg}(21.9 \mathrm{kDa}, 570$ nt), NIa (27.5 kDa, $738 \mathrm{nt})$, NIb (59.6 kDa, 1,554 nt), and CP $(31.0 \mathrm{kDa}, 816 \mathrm{nt})$. The putative cleavage sites in DeCMV polypeptide were identified according to the conserved cleavage sites reported by Adams et al. (2005a) (Fig. 4B). The DeCMV ORF shared 54.1 to $57.3 \%$ nucleotide sequence identity and 43.7 to $49.5 \%$ amino acid sequence identity with those of 24 potyviruses deposited in GenBank (Table 2). Phylogenetic analysis of DeCMV ORF polypeptide and $\mathrm{CP}$ amino acid sequences with those of other potyviruses revealed that DeCMV was clearly distinct from other potyviruses (Fig. 5).
Field survey and identification of DeCMV. In 2017, dendrobium orchid (plant ID 106-De-1) leaves exhibiting chlorotic and mosaic symptoms were collected from a different township in Taiwan. ELISA tests using polyclonal antiserum against DeCMV resulted in weak positive reactions with crude saps prepared from the symptomatic dendrobium orchid (data not shown). An expected 1.4-kb fragment was obtained from 106-De-1 by RT-PCR with Hrp5/ Oligo $\mathrm{d}(\mathrm{T})_{18}$ primers. Sequence comparisons of $\mathrm{CP}$ sequences obtained from 98-De-31 (MK241979) and 106-De-1 (MK241980) revealed that both $\mathrm{CP}$-coding sequence (816 nt, 272 amino acids) shared $83.9 \%$ nucleotide identity and $90.1 \%$ amino acid identity. The CP of DeCMV identified in 106-De-1 had a calculated molecular mass of $30.8 \mathrm{kDa}$, which was slightly smaller than that of DeCMV identified in 98-De-31 (Fig. 3). Two primers (FJJ 201769 and FJJ 2017-70) were synthesized based on conserved sequences within the CP-coding region and used to detect DeCMV. The specificity of the primers was tested further in RT-PCR. The primers amplified an expected 0.54-kb DNA fragment from viral RNA prepared from both 98-De-31 and 106-De-1, two orchids after mechanical inoculation and two orchids after being grafted with 98-De-31 (Fig. 4C).

\section{Discussion}

Dendrobium orchid is one of the most popular flowering plants in Taiwan. More than 57 viral species have been known to infect orchid

A
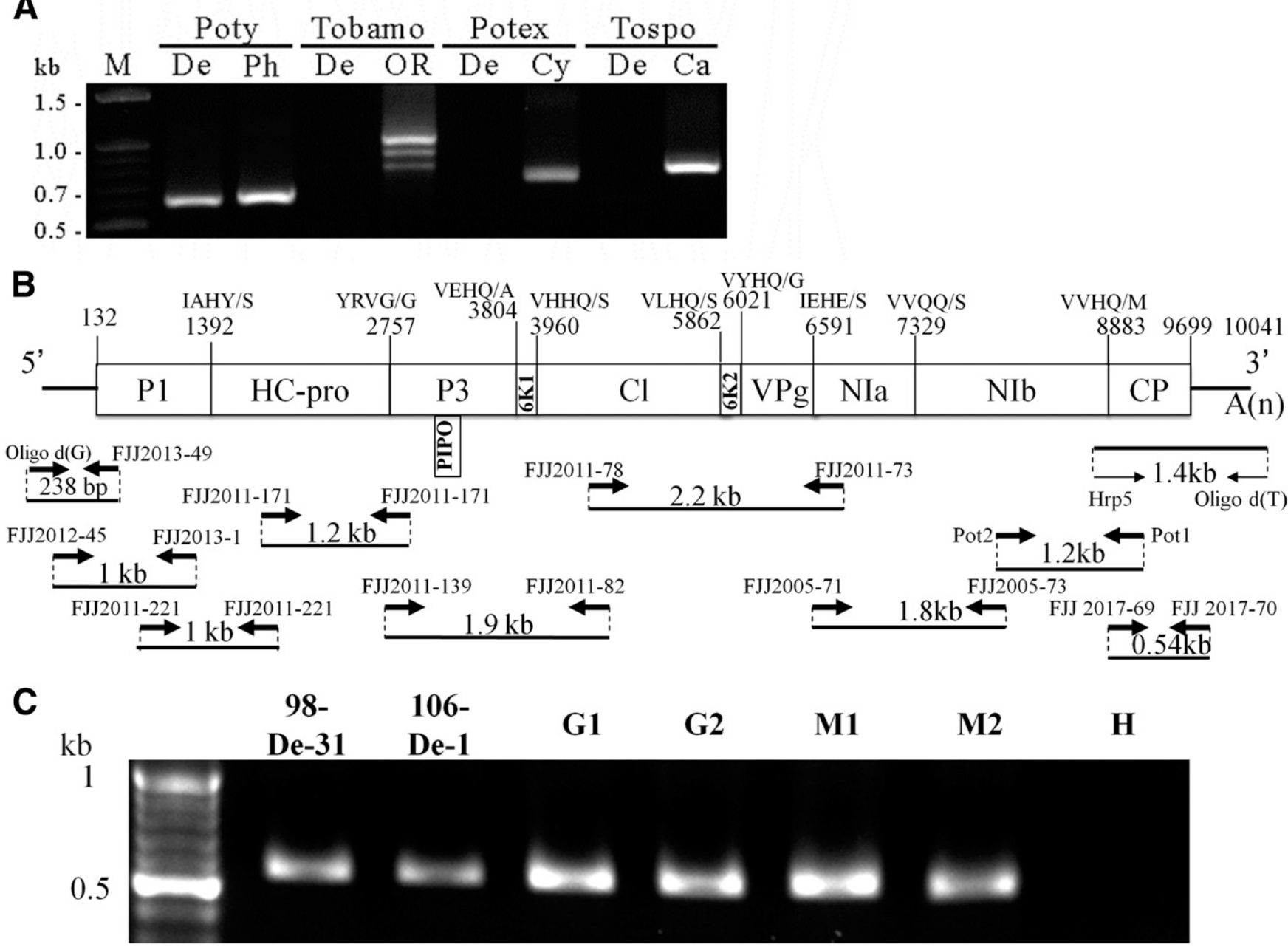

Fig. 4. Reverse transcription polymerase chain reaction (RT-PCR) detection of Dendrobium chlorotic mosaic virus (DeCMV) using total RNA purified from a symptomatic dendrobium orchid 98-De-31. A, RT-PCR detection using degenerate primers for Potyvirus (Poty), Tobamovirus (Tobamo), Potexvirus (Potex), and Tospovirus (Tospo). Labels of lanes: $\mathrm{De}=$ dendrobium orchid 98-De-31; Ph = PhCSV-infected C. quinoa; OR = ORSV-infected orchid; Cy = CymMV-infected orchid; Ca = CaCV-infected C. quinoa; and $\mathrm{M}=$ DNA marker. (Virus abbreviations are defined in the text.) $\mathbf{B}$, Amplification of nine overlapping cDNA fragments from 98-De-31 with the primers indicated (primers are defined in Table 1). All fragments were sequenced and the whole 98-De-31 genome was assembled. C, Amplification of a DeCMV coat protein-coding gene fragment with specific primers FJJ 2017-69 with FJJ 2017-70 from 98-De-31 and 106-De-1 plants and from dendrobium orchids after being grafted (G1 and G2) or inoculated mechanically (M1 and M2) with 98-De-31 stems or crude saps, respectively. Plants treated with $0.01 \mathrm{M}$ phosphate buffer were used as negative controls (H). 
worldwide (Lee et al. 2016). Only CymMV, ORSV, CMV, OFV, CarMV, PhCSV, and CaCV-Ph have been reported to infect orchids in Taiwan. Of them, only CymMV, ORSV, and CMV have been reported to infect dendrobium orchids. Dendrobium orchid (plant ID 98-De-31) leaves showing chlorotic symptoms were observed in an orchid farm located in central Taiwan in 2009. In this work, we have characterized a new potyvirus tentatively named DeCMV as the putative causative agent of a diseased dendrobium orchid showing chlorotic and mosaic symptoms. Indirect ELISA analyses revealed that 98 -De-31 crude saps reacted negatively with antibodies against ORSV, CymMV, CMV, CaCV, and CarMV but reacted positively with monoclonal antibody against potyvirus group. Initial attempts to infect 16 indicator plants using crude saps prepared from the 98 -De-31 orchid by the mechanical inoculation method failed to transfer the virus into these indicator plants. However, similar symptoms were reproduced in dendrobium orchids grafted with scions from 98-De-31 or mechanically inoculated with its crude saps.

The criteria for potyvirus species demarcation are primarily based on the sequence identity of large ORFs. When the overall ORF sequences of an unknown viral isolate show less than $76 \%$ nucleotide identity and $82 \%$ amino acid identity compared with those of other potyviruses, the virus can be classified as a new species of potyvirus (Adams et al. 2005b; Wylie et al. 2017). When the complete ORF sequence is not available, similar criteria can also be used to define a new species based on the identity of the CP (Wylie et al. 2017). In the current study, sequence analysis revealed that the complete ORF sequence of DeCMV shares less than $57.3 \%$ nucleotide sequence and $49.5 \%$ amino acid sequence identity with those of other potyviruses. This indicates that DeCMV is a new potyvirus. Phylogenetic analysis of polyprotein and $\mathrm{CP}$ amino acid sequences also revealed that DeCMV is genetically distinct from other potyviruses (Fig. 5). Comparison of CP amino acid sequences revealed that DeCMV is most similar to Ornithogalum mosaic virus (OrMV), a potyvirus infecting Ornithogalum spp. (Burger and Von Wechmar 1989). However, DeCMV and OrMV are grouped into different clades in polygenetic analysis (Fig. 5B) because DeCMV and OrMV CP sequences share only $66.0 \%$ amino acid identity. Nevertheless, our data points to the fact that DeCMV is a new potyvirus causing chlorotic and mosaic symptoms in dendrobium orchids.

Of 57 plant viruses reported to infect orchids, 21 are potyviruses (Lee et al. 2016; Zheng et al. 2010). Among them, only DeMV and CerMV have been reported to infect dendrobium orchids. Comparison of CP amino acid sequences revealed that DeCMV shares $60.9 \%$ identity with DeMV and $63.2 \%$ identity with CerMV.

In the present study, we demonstrated that plants belonging to the families of Chenopodiaceae, Cucurbitaceae, Solanaceae, Leguminosae, and Orchidaceae are not experimental hosts for DeCMV even though they are commonly used as indicator hosts for many plant viruses. None of those plant families after being mechanically inoculated with 98-De-31 crude saps developed visible symptoms. The narrow host range of DeCMV may be owing to the uniqueness of the P1 protein. Among the 10 proteins produced by the potyviral polypeptide, $\mathrm{P} 1$ is the most divergent in terms of length and amino acid sequence (Mengual-Chulia et al. 2016; Valli et al. 2007). Sequence comparison revealed that the $\mathrm{P} 1$ amino acid sequence of DeCMV shares less than $30 \%$ identities with those of other potyviruses. P1 has been shown to be required for host adaptation in Plum pox virus and other potyviruses (Bejerman et al. 2010; Chiang et al. 2007; Maliogka et al. 2012; Salvador et al. 2008; Valli et al. 2007; Yang et al. 2011). It is
A

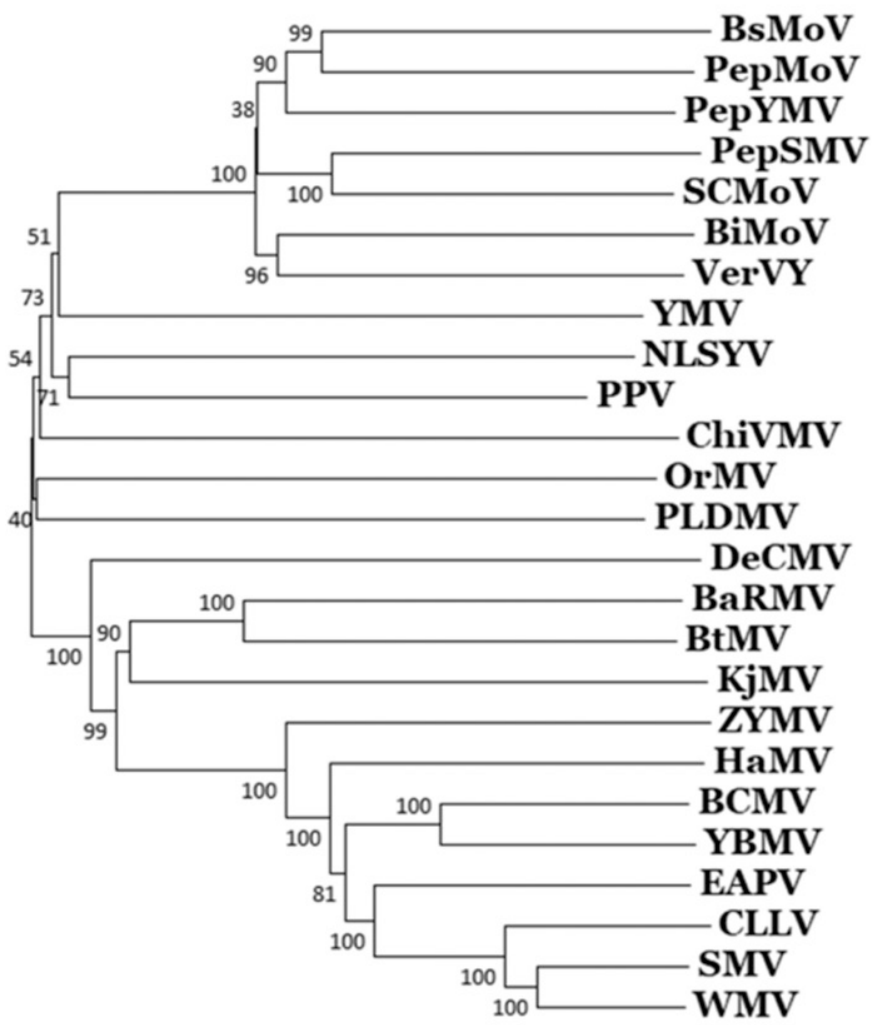

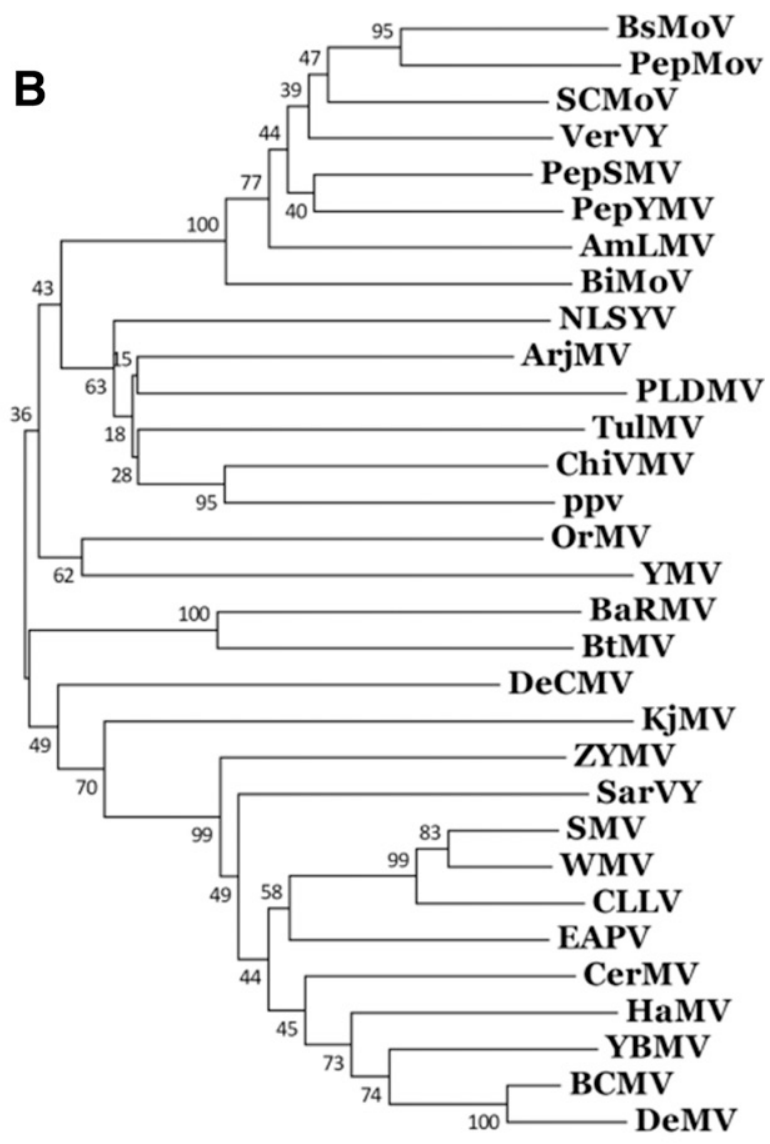

0.050

0.050

Fig. 5. Phylogenetic relationships of the deduced amino acid sequences of polyprotein $(\mathbf{A})$ and coat protein (B) of Dendrobium chlorotic mosaic virus with other potyviruses. Sequence sources are listed in Table 2. The phylogenetic tree was generated by the neighbor-joining method with 1,000 bootstrap replicates using MEGA7 software. 
tempting to speculate that $\mathrm{P} 1$ protein may play a similar role in determining the host range of DeCMV.

A field survey revealed that DeCMV rarely affected dendrobium orchids in Taiwan. The reasons for this rareness of DeCMV remain unknown. It could be owing to the narrow host range of DeCMV or to the lack of proper identification of viral pathogens in dendrobium orchids. Alternatively, lack of appropriate vectors for DeCMV may limit its transmission and spread. DeCMV is likely transmitted by aphids, because its sequence contains several conserved motifs, including a KITC motif and a PTK motif in HC-Pro and a DAG motif in CP. Those motifs have been shown to be involved in aphid transmission in potyviruses (Atreya et al. 1991; Revers and García 2015). Whether or not aphid readily transmits DeCMV requires further examination. Dendrobium orchid plants after being inoculated with DeCMV by mechanical means (4/4, numbers of plants exhibiting symptoms/numbers of plants inoculated) or grafting $(5 / 5$, numbers of plants exhibiting symptoms/numbers of plants grafted) all developed systemic chlorotic symptoms resembling those present on the original plant (98-De-31) 2.5 months after inoculation. The experiments confirm DeCMV infectivity in dendrobium orchids. After the first dendrobium plant (98-De-31) showing chlorotic and mosaic symptoms was identified in 2009 , no diseased dendrobium orchids with similar symptoms were observed until 2017. A polyclonal antiserum against DeCMV was generated and used in ELISA to examine a symptomatic dendrobium orchid (106-De-1) collected in 2017 that resulted in a weak positive reaction. The molecular weight of $\mathrm{CP}$ amino acid was predicted for $98-\mathrm{De}-31$ of about $31 \mathrm{kDa}$ and for 106-De-1 of about $30.8 \mathrm{kDa}$; thus, western blot lane 2 (106-De-1 $\mathrm{CP}$ ) was smaller than those in the other lanes (Fig. 3). This is likely owing to low similarities of CP sequence between the two DeCMV isolates.

Sequence comparison of CPs obtained from 98-De-31 and 106De-1 samples reveals $83.9 \%$ nucleotide identity and $90.1 \%$ amino acid identity, greater than the currently accepted threshold for potyvirus species demarcation. Thus, the putative causative viruses found in 98-De-31 and 106-De-1 are closely related isolates of DeCMV. Based on the biological, pathological, and molecular characteristics of the virus, we conclude that DeCMV is a new potyvirus capable of infecting dendrobium orchids. To our best knowledge, this is the first report of a potyvirus that infects dendrobium orchids in Taiwan.

\section{Acknowledgments}

We are grateful to Dr. Kuang-Ren Chung, Distinguished Professor of the National Chung Hsing University, for their critical editing and review of the manuscript.

\section{Literature Cited}

Adams, M. J., Antoniw, J. F., and Beaudoin, F. 2005a. Overview and analysis of the polyprotein cleavage sites in the family Potyviridae. Mol. Plant Pathol. 6: 471-487.

Adams, M. J., Antoniw, J. F., Fauquet, C. M. 2005b. Molecular criteria for genus and species discrimination within the family Potyviridae. Arch. Virol. 150: 459-479.

Adams, M. J., Zerbini, F. M., French, R., Rabenstein, F., Stenger, D. C., and Valkonen, J. P. T. 2012. Family Potyviridae. Pages 1069-1089 in: Virus Taxonomy, Ninth Report of the International Committee on Taxonomy of Viruses. A. M. Q. King, M. J. Adams, E. B. Carstens, and E. J. Lefkowitz, eds. Elsevier Academic Press, London, U.K.

Atreya, P. L., Atreya, C. D., and Pirone, T. P. 1991. Amino acid substitutions in the coat protein result in loss of insect transmissibility of a plant virus. Proc. Natl. Acad. Sci. U.S.A. 88:7887-7891.

Bejerman, N., Giolitti, F., de Breuil, S., and Lenardon, S. 2010. Molecular characterization of Sunflower chlorotic mottle virus: A member of a distinct species in the genus Potyvirus. Arch. Virol. 155:1331-1335.

Burger, J. B., and Von Wechmar, M. B. 1989. Purification and some properties of South African isolates of Ornithogalum mosaic virus. Phytopathology 79: 385-391.

Chang, H.-H., Ku, H.-M., Tsai, W.-S., Chien, R.-C., and Jan, F.-J. 2010. Identification and characterization of a mechanical transmissible begomovirus causing leaf curl on oriental melon. Eur. J. Plant Pathol. 127:219-228.

Chen, C. C., Chen, T. C., Lin, Y. H., Yeh, S. D., and Hsu, H. T. 2005. A chlorotic spot disease on calla lilies (Zantedeschia spp.) is caused by a tospovirus serologically but distantly related to Watermelon silver mottle virus. Plant Dis. 89:440-445.

Chen, C.-C., Hsu, H.-T., Cheng, Y.-H., Huang, C.-H., Liao, J.-Y., Tsai, H.-T., and Chang, C.-A. 2006. Molecular and serological characterization of a distinct potyvirus causing latent infection in calla lilies. Bot. Stud. (Taipei, Taiwan) 47:369-378.

Chiang, C.-H., Lee, C.-Y., Wang, C. H., Jan, F.-J., Lin, S.-S., Chen, T.-C., Raja, J., and Yeh, S.-D. 2007. Genetic analysis of an attenuated Papaya ringspot virus strain applied for cross-protection. Eur. J. Plant Pathol. 118:333-348.

Chu, F.-H., Chao, C.-H., Chung, M.-H., Chen, C.-C., and Yeh, S.-D. 2001 Completion of the genome sequence of Watermelon silver mottle virus and utilization of degenerate primers for detecting tospoviruses in five serogroups. Phytopathology 91:361-368.

Chung, B. Y., Miller, W. A., Atkins, J. F., and Firth, A. E. 2008. An overlapping essential gene in the Potyviridae. Proc. Natl. Acad. Sci. U.S.A. 105:5897-5902.

Colinet, D., and Kummert, J. 1993. Identification of a sweet potato feathery mottle virus isolate from China (SPFMV-CH) by the polymerase chain reaction with degenerate primers. J. Virol. Methods 45:149-159.

Dijkstra, J., and de Jager, C. P. 1998. Virus transmission by grafting. Pages 116-124 in: Practical Plant Virology: Protocols and Exercises. J. Dijkstra and C. P. de Jager, eds. Springer, Berlin, Germany.

Fernando, S. S., and Ormerod, P. 2008. An annotated checklist of the orchids of Sri Lanka. Rheedea 18:1-28.

Gibbs, A., Armstrong, J., Mackenzie, A. M., and Weiller, G. F. 1998. The GPRIME package: Computer programs for identifying the best regions of aligned genes to target in nucleic acid hybridisation-based diagnostic tests, and their use with plant viruses. J. Virol. Methods 74:67-76.

Hsieh Shih, P.-Y., and Han, Y.-S. 1975. Virus disease of orchids caused by cymbidium mosaic virus in Taiwan. J. Chin. Soc. Hortic. Sci. 21:292-298.

Hu, J. S., Ferreria, S., Wang, M., Borth, W. B., Mink, G., and Jordan, R. 1995 Purification, host range, serology, and partial sequencing of Dendrobium mosaic potyvirus, a new member of the bean common mosaic virus subgroup. Phytopathology 85:542-546.

Hu, J. S., Ferreira, S., Wang, M., and Xu, M. Q. 1993. Detection of cymbidium mosaic virus, odontoglossum ringspot virus, tomato spotted wilt virus, and potyviruses infecting orchids in Hawaii. Plant Dis. 77:464-468.

Inouye, N. 1969. Cucumber mosaic virus isolated from Dendrobium. Agric. Res. 53:49-60

Inouye, N. 1976. Dendrobium mosaic virus. Ber. Ohara Inst. Landw. Biol. Okayama Univ. 16:165-174.

Inouye, N., and Leu, L. S. 1983. Survey on the viruses in orchids in Taiwan. Nogaku Kenkyu. 60:91-110.

Jan, F.-J., Fagoaga, C., Pang, S. Z., and Gonsalves, D. 2000. A single chimeric transgene derived from two distinct viruses confers multi-virus resistance in transgenic plants through homology-dependent gene silencing. J. Gen. Virol. 81:2103-2109.

Jan, F.-J., and Yeh, S.-D. 1995. Purification, in situ localization, and comparative serological properties of passionfruit woodiness virus-encoded amorphou inclusion protein and two other virus proteins. Phytopathology 85:64-71.

Jensen, D. D., and Gold, A. H. 1951. A virus ring spot of odontoglossum orchid: Symptoms, transmission, and electron microscopy. Phytopathology 41: 648-653.

Karasev, A. V., and Gray, S. M. 2013. Continuous and emerging challenges of potato virus $\mathrm{Y}$ in potato. Annu. Rev. Phytopathol. 51:571-586.

Ko, N. J. 1988. Cytological identification of cucumber mosaic virus infecting Phalaenopsis. Proc. Natl. Sci. Counc. Repub. China B 12:46-51.

Kondo, H., Maeda, T., and Tamada, T. 2003. Orchid fleck virus: Brevipalpus californicus mite transmission, biological properties and genome structure. Exp. Appl. Acarol. 30:215-223.

Kumar, S., Stecher, G., and Tamura, K. 2016. MEGA7: Molecular Evolutionary Genetics Analysis version 7.0 for bigger datasets. Mol. Biol. Evol. 33 $1870-1874$

Lawson, R. H., and Hsu, H. T. 1995. Orchid. Pages 409-420 in: Virus and Viruslike Diseases of Bulb and Flower Crops. G. Loebenstein, R. H. Lawson, and A A. Brunt, eds. Wiley, Chichester, U.K

Lee, C.-H., Zheng, Y.-X., and Jan, F.-J. 2016. The orchid-infecting viruses found in the 21st century. Pages 145-164 in: Orchid Biotechnology III. W.-H. Chen and H.-H. Chen, eds. World Scientific, Singapore.

Lesemann, D. E. 1977. Long, filamentous virus-like particles associated with vein necrosis of Dendrobium phalaenopsis. J. Phytopathol. 89:330-339.

Letschert, B., Adam, G., Lesemann, D.-E., Willingmann, P., and Heinze, C. 2002 Detection and differentiation of serologically cross-reacting tobamoviruses of economical importance by RT-PCR and RT-PCR-RFLP. J. Virol. Methods 106:1-10.

Mackenzie, A. M., Nolan, M., Wei, K. J., Clements, M. A., Gowanlock, D., Wallace, B. J., and Gibbs, A. J. 1998. Ceratobium mosaic potyvirus: Another virus from orchids. Arch. Virol. 143:903-914.

Maliogka, V. I., Salvador, B., Carbonell, A., Saenz, P., Leon, D. S., Oliveros, J. C., Delgadillo, M. O., Garcia, J. A., and Simon-Mateo, C. 2012. Virus variants with differences in the P1 protein coexist in a plum pox virus population and display particular host-dependent pathogenicity features. Mol. Plant Pathol. 13:877-886. 
Mengual-Chulia, B., Bedhomme, S., Lafforgue, G., Elena, S. F., and Bravo, I. G. 2016. Assessing parallel gene histories in viral genomes. BMC Evol. Biol. 16:32.

Napoli, C., Lemieux, C., and Jorgensen, R. 1990. Introduction of a chimeric chalcone synthase gene into petunia results in reversible co-suppression of homologous genes in trans. Plant Cell 2:279-289.

Ng, J. C. K., and Perry, K. L. 2004. Transmission of plant viruses by aphid vectors. Mol. Plant Pathol. 5:505-511.

Olspert, A., Chung, B. Y., Atkins, J. F., Carr, J. P., and Firth, A. E. 2015. Transcriptional slippage in the positive-sense RNA virus family Potyviridae. EMBO Rep. 16:995-1004.

Revers, F., and García, J. A. 2015. Molecular biology of potyviruses. Adv. Virus Res. 92:101-199.

Riechmann, J., Lain, L., and García, J. A. 1992. Highlights and prospects of potyvirus molecular biology. J. Gen. Virol. 73:1-16.

Rodamilans, B., Valli, A., Mingot, A., San León, D., Baulcombe, D., Lopez-Moya, J. J., and Garcia, J. A. 2015. RNA polymerase slippage as a mechanism for the production of frameshift gene products in plant viruses of the Potyviridae family. J. Virol. 89:6965-6967.

Rybicki, E. P., and Shukla, D. D. 1992. Coat protein phylogeny and systematics of potyviruses. Arch. Virol. Suppl. 5:139-170.

Salvador, B., Saenz, P., Yanguez, E., Quiot, J., Quiot, L., Delgadillo, M. O., Garcia, J. A., and Mateo, C. S. 2008. Host specific effect of P1 exchange between two potyviruses. Mol. Plant Pathol. 9:147-155.

Shukla, D. D., Ward, C. W., and Brunt, A. A. 1994. The Potyviridae. CAB International, Wallingford, U.K.

Takamiya, T., Wongsawad, P., Tajima, N., Shioda, N., Lu, J. F., Wen, C. L., Wu, J. B., Handa, T., Iijima, H., Kitanaka, S., and Yukawaf, T. 2011. Identification of Dendrobium species used for herbal medicines based on ribosomal DNA internal transcribed spacer sequence. Biol. Pharm. Bull. 34: 779-782.

Urcuqui-Inchima, S., Anne-Lise, H., and Bernardi, F. 2001. Potyvirus proteins: A wealth of functions. Virus Res. 74:157-175.
Valli, A., Lopez-Moya, J. J., Garcia, J. A. 2007. Recombination and gene duplication in the evolutionary diversification of P1 proteins in the family Potyviridae. J. Gen. Virol. 88:1016-1028.

Wey, G. C. 1988. Occurrence and investigation of important diseases on Phalaenopsis in Taiwan. Rep. Taiwan Sugar Res. Inst. 122:31-41.

Wylie, S. J., Adams, M., Chalam, C., Kreuze, J., López-Moya, J. J., Ohshima, K., Praveen, S., Rabenstein, F., Stenger, D., Wang, A., and Zerbini, F. M. 2017. ICTV virus taxonomy profile. Potyviridae. J. Gen. Virol. 98:352-354.

Yan, L., Wang, X., Liu, H., Tian, Y., Lian, J., Yang, R., Hao, S., Wang, X., Yang, S., Li, Q., Qi, S., Kui, L., Okpekum, M., Ma, X., Zhang, J., Ding, Z., Zhang, G., Wang, W., Dong, Y., and Sheng, J. 2015. The genome of Dendrobium officinale illuminates the biology of the important traditional Chinese orchid herb. Mol. Plant 8:922-934.

Yang, Y., Gong, J., Li, H., Li, C., Wang, D., Li, K., and Zhi, H. 2011. Identification of a novel Soybean mosaic virus isolate in China that contains a unique 5 terminus sharing high sequence homology with Bean common mosaic virus. Virus Res. 157:13-18

Zettler, F. W., Ko, N.-J., Wisler, G. C., Elliott, M. S., and Wong, S.-M. 1990 Viruses of orchids and their control. Plant Dis. 74:621-626.

Zhang, Q., Ding, Y. M., and Li, M. 2010. First report of impatiens necrotic spot virus infecting phalaenopsis and dendrobium orchids in Yunnan province, China. Plant Dis. 94:915.

Zheng, Y.-X., Chen, C.-C., Chen, Y.-K., and Jan, F.-J. 2008a. Identification and characterization of a potyvirus causing chlorotic spots on phalaenopsis orchids. Eur. J. Plant Pathol. 121:87-95.

Zheng, Y.-X., Chen, C.-C., and Jan, F.-J. 2011. First report of carnation mottle virus in phalaenopsis orchids. Plant Dis. 95:354.

Zheng, Y.-X., Chen, C.-C., Yang, C.-J., Yeh, S.-D., and Jan, F.-J. 2008b Identification and characterization of a tospovirus causing chlorotic ringspots on Phalaenopsis orchids. Eur. J. Plant Pathol. 120:199-209.

Zheng, Y.-X., Shen, B.-N., Chen, C.-C., and Jan, F.-J. 2010. Odontoglossum ringspot virus causing flower crinkle in phalaenopsis hybrids. Eur. J. Plan Pathol. 128:1-5. 